open $\bigcirc$ Access

\author{
Authors' contribution: \\ A) conception and design \\ of the study \\ B) acquisition of data \\ C) analysis and interpretation \\ of data \\ D) manuscript preparation \\ E) obtaining funding
}

Received: 04.08 .2020

Accepted: 22.03.2021

\section{Individual knowledge of, perceptions about, and barriers to physical literacy (PL) in Malaysia}

\author{
Ahmad Fahim Zulkifli ${ }^{*}$ A-E (D, Ajau Danis ${ }^{2 A-C}$ (i) \\ ${ }^{1}$ Faculty of Health Science, Faculty of Education, Universiti Teknologi MARA (UiTM), \\ 42300 Bandar Puncak Alam Selangor, Malaysia \\ ${ }^{2}$ Faculty of Health Science, Universiti Teknologi MARA (UiTM), 42300 Bandar Puncak \\ Alam Selangor, Malaysia
}

*Correspondence: Ahmad Fahim Zulkifli, Fakulti Pendidikan, Bangunan FSK 1,5 Kampus Puncak Alam 42300 Bandar Puncak Alam, Selangor Malaysia; email: fahimzulkifli@uitm.edu.my

\begin{abstract}
The purpose of this study was to evaluate individuals' knowledge of, perceptions about, and barriers to promoting physical literacy (PL) in Malaysia. Random samples of 360 participants of different genders, ages, races, and education levels (aged 15-60 years) residing in Malaysia participated in this study, which was conducted on online platforms between the months of February and May, 2019. The participants' knowledge was assessed using a modified Physical Literacy Knowledge questionnaire (PLKQ). Open-ended questions were also conducted to assess perceived perceptions and barriers to improving participants' PL, thus strengthening the validity and reliability of data collection. Quantitative data were analyzed using descriptive statistics (e.g., means, SD) and the Pearson correlation coefficient, while the analysis of qualitative data involved the usage of the Interpretive Phenomenological Approach (IPA). The participants showed greater efficacy about standards in physical education and believed that PL is developed throughout one's lifetime, with $(\mathrm{M}=3.2, \mathrm{SD}=1.02)$ and $(\mathrm{M}=3.78, \mathrm{SD}=1.02)$, respectively. Additionally, most participants pointed to the necessity of having specific skills and experience to develop PL among young people as the main barrier to improving PL in Malaysia, with $(\mathrm{M}=3.25, \mathrm{SD}=1.02)$. This initial study will provide better direction for future researchers and educators to plan an intervention to increase PL among Malaysians and advocate for physical activity in individuals' daily lives. Additionally, this study will be useful to inform future educators' teaching practices, particularly in Malaysian schools.
\end{abstract}

Key words: physical literacy, physical education, physical activity, teaching, learning

\title{
Introduction
}

The rationale for this study came from the author's observations and communication with undergraduate students from the Faculty of Education at the local university of Central Malaysia. Most of the students (aged 19-30 years old) appeared to be unsure and confused about the concept of physical literacy (PL). They associated PL with adolescents learning sports skills and eventually becoming skillful in their particular sport. Additionally, the students viewed PL as essential only for those involved in sports and physical education (PE). Unfortunately, some of the students also regarded PL as less important than writing, reading, and numerical literacy. The national health survey reported that as many as $25.1 \%$ of Malaysians are physically inactive (Institute for Public Health, 2019), and 
this inactivity has contributed to as much as $16.4 \%$ of deaths related to sedentariness (Lee et al., 2012; Khoo et al., 2020). Thus, this initial project was designed to seek evidence concerning the understanding and importance of PL and determine starting points for planned interventions to increase PL among Malaysians.

Many studies on PL found some Malaysian local schools' policies were inconsistent with national standards and preferred to reduce PE time from the recommended 32 hours/year (primary) and 48 hours/year (secondary), contributing to lower skill competencies (Ministry of Education Malaysia, 2019). Apart from time, the number of students in primary and high school continued to rose from $0.7 \%$ to $3.1 \%$ in 2018 compared to the previous year, while the number of teachers in both levels declined from 0.5\% to 2.2\% (Department of Statistics Malaysia, 2019). Apart from the short period of time spent in PE and the imbalanced ratios between teachers and students, insufficient equipment and teachers' insufficient content knowledge and pedagogical and technological skills were all blamed for students' lower skill levels (Castilli \& Valley, 2007; Graham, 2015). Choi et al. (2018) further explained that PL is essential in developing basic skills, enabling individuals to master many complex skills such as the cartwheel, basketball jump-shot, and knotting. Despite its importance, Malaysians were still unaware of, unconcerned about, hesitant about, and resistant to the concept of PL and its potential for many aspects of life (e.g., health, social, economic; Lopes et al., 2017).

The newer generation is more technologically savvy; for instance, 97\% of Malaysians aged 16-64 years old possess a minimum of one smartphone and spend on average eight hours per day with media (e.g., social media, watching TV, streaming services, gaming; Kemp, 2020). Both social networking and chat applications are most preferred, with a preference of $98 \%$ and $97 \%$, respectively, while health and fitness applications are only downloaded by a mere $27 \%$ of Malaysian Internet users (Kemp, 2020). In addition to uncontrolled Internet usage, the current COVID-19 pandemic also increases the likelihood of individuals becoming sedentary and reducing their physical activity (PA) levels. The current situation also contributes to individuals' lack of skills, musculoskeletal and cognitive decline, low self-esteem, low motivation levels, and feelings of alienation from their peers (Bowden Davies et al., 2019; Woods et al., 2020). Due to the insecurity among students, they tend to produce excuses such as a lack of time, fatigue, and laziness to avoid PA (Choi, Sum, Leung, \& Ng, 2018). All these factors in some ways have contributed to the fact that Malaysia currently has the highest rate of obesity in Asia (World Health Organization, 2019).

\section{Physical literacy (PL)}

Physical literacy (PL) is defined as the "motivation, confidence, physical competence, knowledge, and understanding to value and take responsibility for engaging in PA for life" (Whitehead, 2016). In other words, a physically literate individual would enjoy learning the skills, background, and values around sports and appreciate the benefits of engaging in PA. Additionally, PL is considered to be the essence of meaningful PE, which helps students gain confidence in developing mastery in sports skills (Choi et al., 2018).

The positive relationship between PL and PE is beneficial to the individual in many ways. Dudley, Okley, Pearson, and Cotton (2011) found that higher PL would provide an advantage to individuals learning and developing skill proficiencies. PL provides better hand-eye coordination and skill-related fitness (e.g., reaction time, balance, agility), thus helping individuals develop more complex skills such as golf putting, skiing, and cartwheels in gymnastics. An individual's mastery of sports skills is believed to be a crucial factor in lifetime involvement in PA (Logan, Webster, Gretchell, Pfeiffer, \& Robinson, 2015).

Furthermore, several studies have also found that a physically literate individual is versatile, an initiator, and more willing to be involved in a variety of sports in comparison to others with lower levels of PL. Their skill mastery contributes to a higher level of motivation, persistence, and a spirit of adventure, which provides them with higher chances of success when learning new sports skills (Choi et al., 2018). Perhaps the most important benefits of developing PL is the ability to develop a sense of control both internally and externally, which is associated with a feeling of optimism in the individual's life (Seligman, 2002).

\section{Fundamental movement skills (FMS) and PL}

Fundamental movement skills (FMS) are closely associated with an individual's PL. FMS are the basic behaviors and movement patterns developed throughout childhood to adulthood (e.g., running, hopping, dodging, catching). FMS are developed through previously learned movements from reflexive and rudimentary movement phases to advanced skills (O'Brian, Belton, \& Issartel, 2016). Although many individuals originally perceived the development of FMS as part of the process of growing up, several studies have argued that FMS need to be developed through developmentally appropriate activities, personalized teaching and learning strategies, meaningful feedback, and sufficient practice time (Cools et al., 2009; Hardy et al., 2010a; Logan et al., 2015). Several studies 
have also associated a dose-response relationship between these terms; the higher the FMS, the greater the individual's development of PL throughout their lifetime (O'Brian, Belton, \& Issartel, 2016). Studies by both Ennis (2010) and Harten, Olds, and Dollman (2008) have suggested that higher levels of motor skills can be associated with greater play activity and participation in diverse activities throughout an individual's lifetime. Studies dating from the twentieth century have found individuals with FMS deficiencies were more likely to develop lifelong problems with movement skills (Ulrich, 2000). For instance, Mitchell et al. (2013) worked with children and early adolescents (5-13 years old) and found less than half of the participants were proficient in basic FMS such as kicking (21\%), throwing (31\%), and striking (40\%). Although the scores vary from country to country, the majority of studies related to FMS have demonstrated most children and adolescents fail to surpass $50 \%$ mastery in most skills (Hardy et al., 2010b; O'Brian et al., 2016). Therefore, FMS are the foundation for developing a physically literate individual capable of performing many tasks and successfully navigating through physical, mental, and emotional challenges.

\section{The teacher's role in developing PL}

In Malaysia and most other countries around the world, the majority of young people spend much of their time attending school (van Sluijs, McMinn, \& Griffin, 2007; Department of Statistics Malaysia, 2019). Previous studies have also shown the need for young people attending schools to engage in more organized and structured motor skill programs rather than simple play or games (Choi et al., 2018). Therefore, the teacher's role in planning and implement content, managing students and the classroom, and assessing student learning has profound effects on the academic development of students, as well as the development of the individual as a whole (Lopes, Stodden, \& Rodrigues, 2017).

Prioritizing the implementation of strategies for teaching and learning would increase learning ownership among students. In return, students would be more likely to get involved, engage with content, get motivated, and find meaning in their learning (Martinek, 2017; Martinek, Holland, \& Seo, 2019). Additionally, a student-centered approach in the classroom also provides students with more choices and promotes cooperative learning, which helps reduce the fear of failure and increases opportunities for success. Most importantly, teachers should strive to promote PL through contemporary teaching methods (i.e., peer-teaching, videos, role-play, fantasy cards) and increase PA via age-appropriate practices (Choi et al., 2018).

In contrast, the traditional teaching style's emphasis on direct instructions typically results in students disengaging from the content and becoming frustrated (Barnett, Dawes, Morgan, \& Wilmut, 2012). Disregarding individuals' strengths, weaknesses, interests, and backgrounds during the process of teaching also reduces the effectiveness of the content while increasing the chance of off-task behaviors. Similarly, neglecting factors such gender, PA intensity, and type of motor skills also reduces motor skill competencies and the likelihood of lifetime fitness (Feguera \& An, 2017). Unfortunately, weak motor skills affect individuals' self-esteem and motivation to engage in PA, especially in competitive settings (Choi et al., 2018). Additionally, using traditional teaching styles would cause more difficulty for teachers in determining whether students are able to perform skills correctly due to the short period of time for assessment and students' tendency to shy away from trying their best (Marton, 2015).

\section{Purpose}

The current study builds on these previous studies to determine participants' current knowledge of and perceptions towards PL and barriers to PL being equally recognized along with others forms of literacy (e.g., numerical or reading). This study utilizes several methods designed to influence learning domains, including a questionnaire (cognitive) and use of open-ended questions (affective) to increase the validity and reliability of the data. Therefore, the following questions were addressed in this study: (1) Are participants able to introduce and explain the concept of PL? (2) Are participants' perceptions biased toward agreement or disagreement with the concept of PL? (3) What are the main barriers in developing and promoting the concept of PL in schools and the community?

\section{Materials and methods}

\section{Participants}

The participants of this study were random samples of 360 individuals (180 male and 180 female) with an age range of 15-60 years old. Although the sample group included different genders, ages, races, and education levels, the majority of the participants reported having a Malay ethnic background. A total of 26 participants reported 
having other ethnic backgrounds (e.g., Sabahan, Sarawakians), and five reported Chinese ethnicity. The participants were invited to participate in this study via email. Their email addresses were obtained from various local universities in Peninsular Malaysia. Most of the participants initially reported limited knowledge of and experience with the concept of PL. The random sampling was chosen as it provided an equal chance for the public to participate in this study. Apart from ease of use, the sampling technique offered a better representation of the population. Therefore, the researcher was able to make more accurate generalizations from the results to the population (Sharma, 2017).

\section{Setting}

The Progressive University (pseudonym), located in a large suburban area in central Malaysia, was chosen to be the main location for the implementation of the study via online platforms (e.g., email, WhatsApp [Facebook Inc.], Google Form [Google Inc.]). Additionally, the researcher also utilized the non-teaching time to observe PE classes among physical and health education (PHE) undergraduate students to improve observational data on participants' PL. Additionally, the time was also used to conduct literature reviews and plan for using appropriate instruments to achieve the study's objectives. The data collection was conducted between the months of February and May, 2019.

\section{Study design and procedures}

This study adopted the cross-sectional study design due to its capability to estimate the current population's interest in PL. Additionally, this study design was also chosen as it allowed the researcher to obtain the needed information at one time point and in a short period of time (Levin, 2006). Apart from being quick to implement, this design was also inexpensive to conduct and provided meaningful information for future planning and modification of PE. Nonetheless, the design was not able to infer causality as the study was carried out for a short period of time with one time point and provided no prior or post-study information (Levin, 2006).

The researcher utilized the Physical Literacy Knowledge Questionnaire (PLKQ) and open-ended questions to explore and determine participants' current knowledge of, perceptions about, and barriers to PL. The duration of the study was from February to May, 2019. The study primarily focused on gathering initial data concerning individuals' knowledge and perceptions of PL. The participants were given the opportunity to share their thoughts on PL and previous experience related to learning PA without any interference from the author. Nonetheless, the author also took the opportunity to accentuate the importance of PL concepts in skill development and independent learning in the introduction of the questionnaire and open-ended questions. Additionally, the author prompted the participants by initiating situational-related discussions to help them recall their experience with PL and improve connections between understanding and actions.

This study involved several phases: (1) preparation, (2) implementation, and (3) data processing. Prior to the study, the researcher conducted an extensive literature review to gain insights about the issues and plan for implementing the appropriate instruments to achieve the study's objectives. Additionally, instruments were developed and sent for peer review to increase both the validity and fidelity of the study. Next, random samples were invited to participate in the study via the Internet. Their willingness to fill in the questionnaire and answer the open-ended questions indicates their consent to participate in the study. The researcher ensured all information (i.e., aims, objectives, benefits) were included in the instruments and email sent to potential participants. The last phase involved
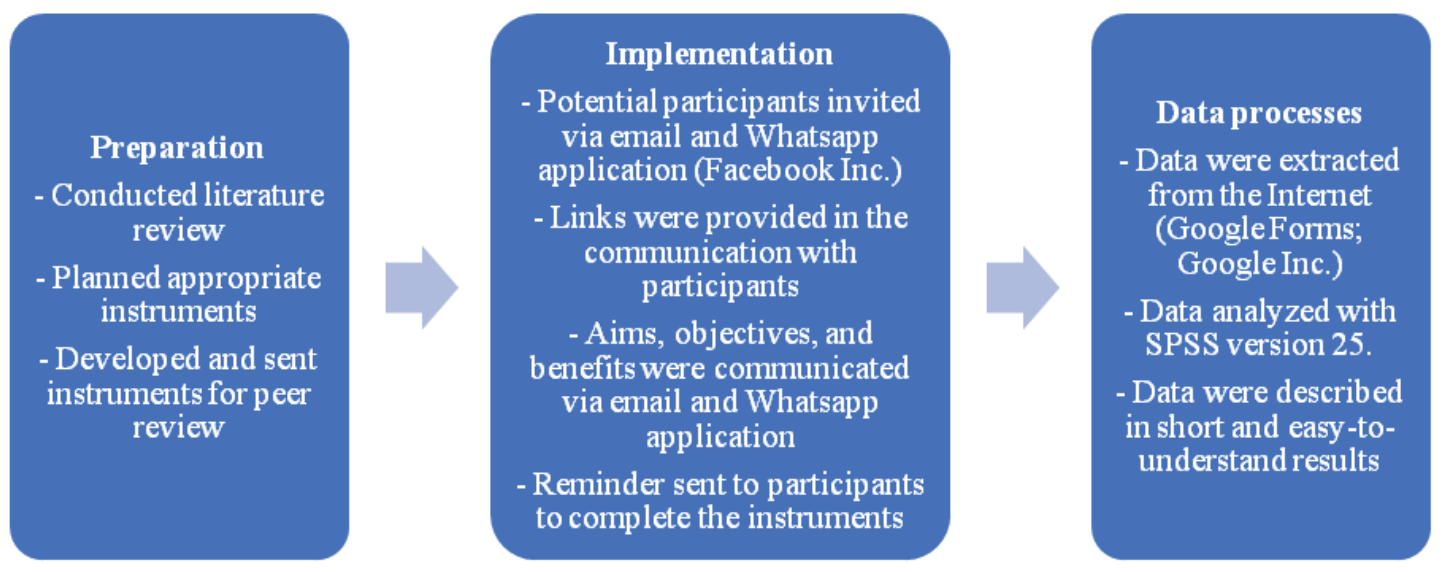

Figure 1. The different phases of the study 
the researcher analyzing the data and producing meaningful information with regards to the study's objectives. The researcher used the results to attempt to formulate a generalization of the knowledge and perceptions of PL among the general population in Peninsular Malaysia. In addition, the researcher proposed several ideas to move forward from this current study. All the participants' details were kept confidential throughout the study, and participants were made fully aware of the purpose and objectives of the study before their consent was obtained.

\section{Instruments}

Modified Physical Literacy Knowledge Questionnaire (PLKQ): This instrument was based on the Physical Literacy Knowledge Questionnaire (PLKQ) as a standard for measuring PL knowledge (Longmuir, Woodruff, Boyer, Lloyd, \& Tremblay, 2018). The modified PLKQ contains 21 questions with knowledge, perception, and barriers components and utilizes a five-point Likert-like scale ranging from low to high $(1=$ very low, $5=$ very high). Specifically, it was used to explore participants' knowledge, feelings, and degree of certainty towards various aspects related to PL. They were asked to self-assess their understanding of various aspects of PL (i.e., skill movement, skill development, standards, policies, educators' roles, facilities). Participants spent approximately 3-5 minutes to complete the questionnaire. The researcher provided a short explanation of the aims, objectives, and benefits of completing the questionnaire to help participants understand and complete the questionnaire in the best manner.

\section{Open-ended questions}

The Interpretive Phenomenological Analysis (IPA) approach was use for the open-ended questions to assess participants' current knowledge and perceptions of the concept of PL (Pietkiewicz \& Smith, 2014). They were given the freedom to express their thoughts and demonstrate their understanding of the influence of PL on their daily activity. There were a total of four questions related to PL. The author asked the participants: (1) What do you understand about PL? (2) Do you consider PL as important as reading and numerical literacy? (3) Would you advocate for PL? (4) What are the barriers for promoting PL among Malaysians? Moreover, the author stressed both in the email and at the beginning of the questions the importance of participants expressing their own thoughts in answering each of the questions. The questions' content, structure, and word selection were sent for peer-review before being administered to the participants.

\section{Data analysis}

Descriptive statistics - that is, mean (M), standard deviation (SD), and percentages - were calculated for variables assessed in the study (knowledge, perceptions, barriers) using the Statistical Package for Social Sciences (SPSS version 25.0; Mills, 2014). Additionally, a test of association between knowledge and perception of PL using the Pearson correlation coefficient was also conducted to gain better insights about PL in Peninsular Malaysia. In short, correlation is described as occurring between the range of -1.00 to +1.00 . A score of -1.00 indicates a negative relationship between the variables, whereas +1.00 indicates a positive relationship between the variables. A score of 0.00 suggests no relationship between the variables (Gratton \& Jones, 2010). Furthermore, data from the open-ended questions were transcribed, extracted, and categorized into four themes: (1) knowledge, (2) perceptions, (3) facilities, and (4) technology. Both quantitative and qualitative data were useful in increasing the validity and reliability of this study. In addition, bar graphs/charts were used to visually demonstrate significant findings qualitatively. Apart from showing the findings, graphs were also beneficial in displaying behavioral changes among participants and interpretations of behaviors, offering meaningful visual feedback for readers (Cooper, Heron, \& Heward, 2007).

\section{Results}

Following the exclusion of 5 participants (i.e., incomplete questionnaire, did not attend meetings), participants consisted of 360 participants from various backgrounds who enrolled in the study during the four-month time frame.

\section{Modified PLKQ}

There were a total of 360 participants, with an equal number of males and females participating in the study. Based on Table 1, the majority of the participants were between the ages of 22 and 30 years old, with 259 (72\%) 
Table 1. Age of respondents

\begin{tabular}{ccc}
\hline Age category & Percent & $\mathrm{n}$ \\
\hline $15-21$ & 22.5 & 81 \\
$22-30$ & 71.9 & 259 \\
$31-59$ & 4.7 & 17 \\
$60+$ & 0.8 & 3 \\
\hline
\end{tabular}

in this age group. A total of $81(22.5 \%)$ participants were in the 15-21 age group. The age groups of 31-59 and $60+$ recorded the least number of participants, with $17(4.7 \%)$ and $3(0.8 \%)$, respectively.

The majority of the participants, $290(80 \%)$, were currently enrolled in an undergraduate program or possessed an undergraduate degree. A total of $54(15 \%)$ possessed various certificates (i.e., high school diplomas, technical or skill certificates), and a minority of participants possessed a doctorate $(\mathrm{n}=4,1 \%)$.

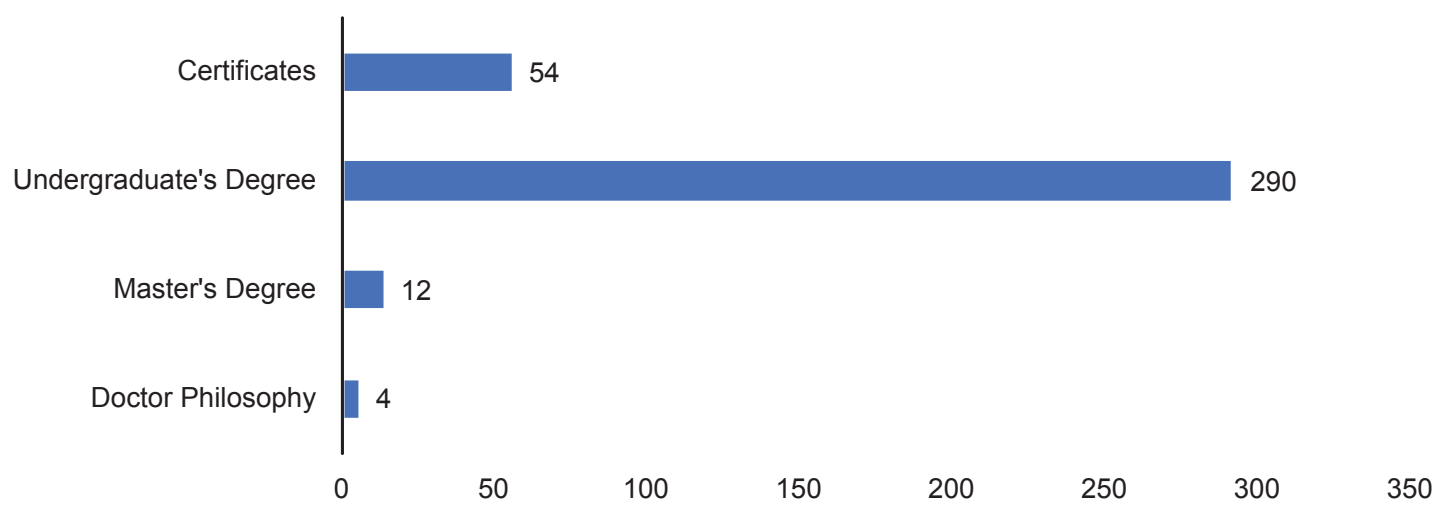

Figure 2. The chart above shows the education levels among the participants

\section{Participants' level of knowledge of the concept of PL}

The participants' level of knowledge of the concept of PL as shown in Figure 3 shows consistency among all questions with the highest scores $(\mathrm{M}=3.2, \mathrm{SD}=1.02)$ found in the descriptor "I know the standards on physical and health education lessons." This was followed by the descriptor "I know the basic of locomotor movements" $(\mathrm{M}=3.14, \mathrm{SD}=1.12)$. Meanwhile, both the descriptors of "I know about the concept of PL" and "I have taught others about PL" recorded the lowest scores among participants with $(\mathrm{M}=3, \mathrm{SD}=1.03)$ and $(\mathrm{M}=2.68, \mathrm{SD}=1.14)$, respectively.

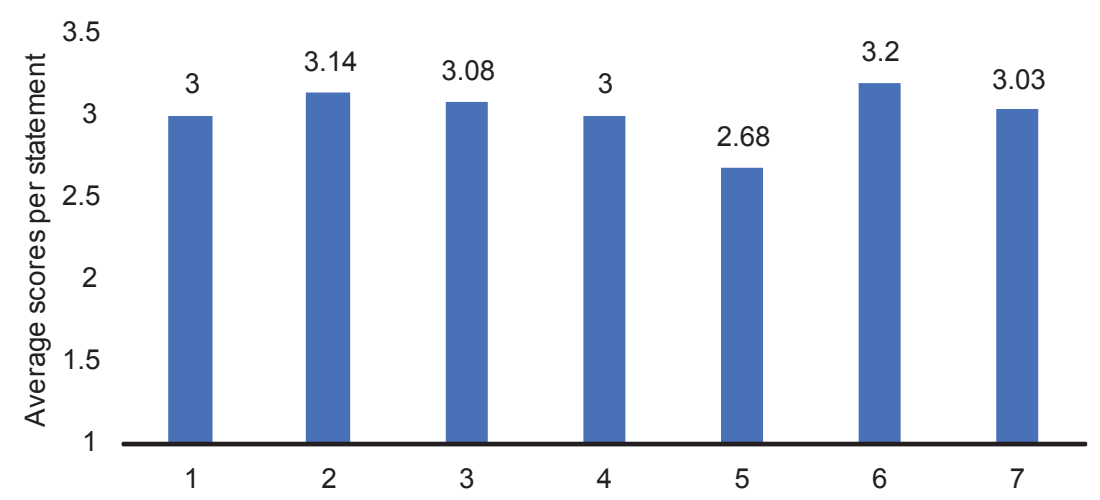

Figure 3. Mean scores of participants' level of knowledge of the concept of PL across the study

\section{Participants' perceptions of the concept of PL}

The participants had lowest confidence in the descriptor "I consider myself as an advocator for PL" $(\mathrm{M}=2.97$, SD = 1.04), while descriptors 10 and 12, "I think PL should only be emphasized at schools" and "I think PL can be developed by itself without specific and structured learning" had similar scores with $(\mathrm{M}=2.98, \mathrm{SD}=1.29)$ and $(\mathrm{M}=2.98, \mathrm{SD}=1.14)$, respectively. Nonetheless, most of the participants agreed with the descriptor "PL is developed throughout one's lifetime" $(\mathrm{M}=3.78, \mathrm{SD}=1.02)$. 


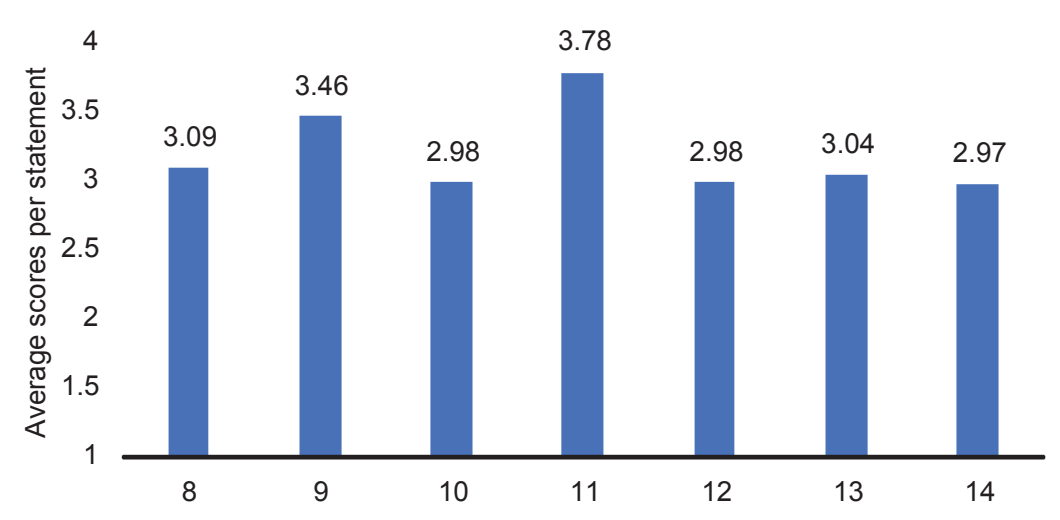

Figure 4. Mean scores of participants' perceptions of the concept of PL across the study

\section{Barriers to promoting PL}

Descriptive statistics results for barriers to promoting PL are presented in Figure 5. Most of the participants pointed to the descriptor "developing PL requires a highly skilled educator" as the main obstacle in promoting the concept of PL in Malaysia $(\mathrm{M}=3.25, \mathrm{SD}=1.02)$. Besides this, many also agreed that the descriptors "developing PL requires complex/specific facilities" and "developing PL requires specific equipment" were crucial for developing and advocating for $\mathrm{PL}$ among Malaysians, with $(\mathrm{M}=2.99, \mathrm{SD}=1.03)$ and $(\mathrm{M}=2.96, \mathrm{SD}=1.07)$, respectively. Additionally, the majority of participants rejected the descriptor "I dislike the concept of PL" as a barrier to promoting PL $(\mathrm{M}=1.93, \mathrm{SD}=0.91)$.

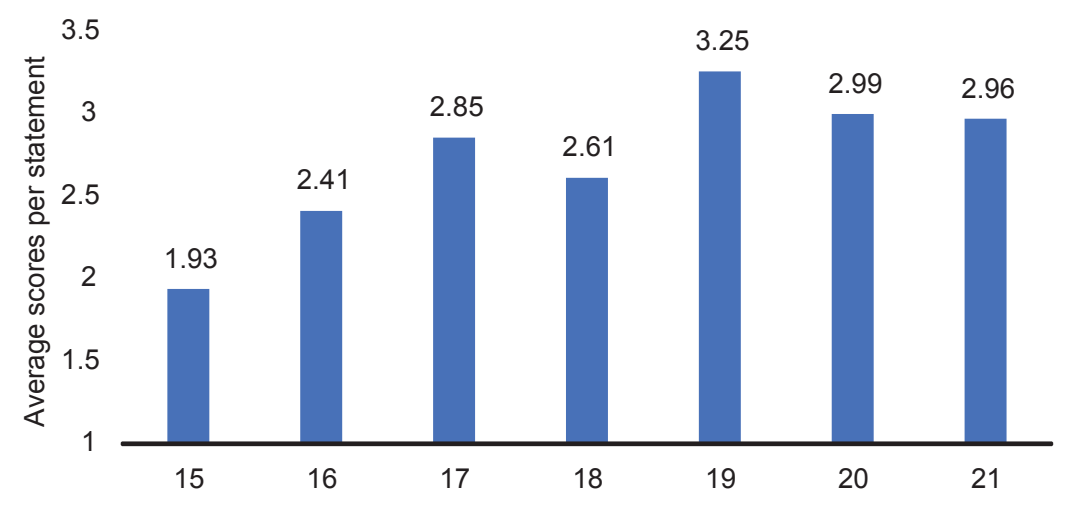

Figure 5. Mean scores of barriers to developing and promoting the concept of PL in Malaysia

\section{The association between knowledge and perceptions of $P L$}

The correlation coefficient results between the highest and lowest descriptor scores for knowledge and perceptions are presented in Table 2 and 3. The Pearson's $r$ in Table 2 demonstrates a moderate positive relationship between the $\mathrm{K} 6$ and P11 descriptors $(r=.406, p=<0.05, n=360)$. The lowest descriptor scores in Table 3 also suggest a moderate positive relationship between the K5 and P14 descriptors $(r=.628, p=<0.05, n=360)$. As the 2 -tailed significance value is $<.000$, this study will assume the correlation to be significant and not due to sampling error. Therefore, having knowledge may develop participants' perceptions of PL, whereas an individual's perception will either motivate or demotivate their effort to obtain knowledge related to PL.

\section{Discussion}

\section{Knowledge of the concept of PL}

The majority of the participants reported average to poor knowledge and understanding of the concept of PL and its functions and benefits to the development of individuals. The respondents from non-sports backgrounds 
Table 2. The correlation between the highest descriptor scores

\begin{tabular}{llcc}
\hline & & K6 & P11 \\
\hline $\begin{array}{l}\text { I know the } \\
\text { standard of PHE } \\
\text { lessons (K6) }\end{array}$ & $\begin{array}{l}\text { Pearson } \\
\text { correlation }\end{array}$ & 1 & $.406^{* *}$ \\
& Sig. (2-tailed) & & .000 \\
& $\mathrm{~N}$ & 360 & 360 \\
\hline $\begin{array}{l}\text { PL is developed } \\
\text { throughout one's }\end{array}$ & $\begin{array}{l}\text { Pearson } \\
\text { correlation }\end{array}$ & $.406^{* *}$ & 1 \\
& Sig. (2-tailed) & .000 & \\
\hline$* *$ N Correlation is significant at the 0.01 level (2-tailed).
\end{tabular}

Table 3. The correlation between the lowest descriptor scores

\begin{tabular}{llcc}
\hline & & K5 & P14 \\
\hline $\begin{array}{l}\text { I have taught } \\
\text { others about PL } \\
\text { (K5) }\end{array}$ & $\begin{array}{l}\text { Pearson } \\
\text { correlation }\end{array}$ & 1 & $.628^{* *}$ \\
& Sig. (2-tailed) & & .000 \\
& $\mathrm{~N}$ & 360 & 360 \\
\hline $\begin{array}{l}\text { I consider myself } \\
\begin{array}{l}\text { as an advocator } \\
\text { for PL (P14) }\end{array}\end{array}$ & Sig. (2-tailed) & .000 & \\
& $\mathrm{~N}$ & 360 & 360 \\
\hline
\end{tabular}

** - Correlation is significant at the 0.01 level (2-tailed). especially reported lower familiarity or lack of familiarity with the concept of PL. One of the respondents suggested "I never heard about PL, probably due to my sedentary lifestyle," while another respondent explained "I do not have a clear idea about what PL is as it was not taught during school time." Most of them blamed their lack of knowledge and experience related to PL with the lack of exposure in schools. This issue is in line with the suggestion of Feguera and An (2017) that the traditional teacher-centered learning process causes more students to disengage from the educator and learning content, leads to a higher fear of failure due to lower self-esteem, and results in individuals developing fewer skills throughout their lifetimes. Fortunately, most of the respondents also showed a high interest in getting to know more about PL and learning what they can do to advocate for PL in their community.

Nonetheless, some respondents agreed that PL "helped to develop basic movement skills such as walking, running, skipping, and jumping," "helped to maintain my overall health," "helped me to perform a variety of movements fundamental to confidence and without pain or fear or failure," and "helped individuals achieve optimum physical, emotional, spiritual, intellectual, and social states." As the majority of young people in Malaysia attend school, the educator should invest more time in teaching FMS, including primary and complex skills, during high school. This will help develop PL among newer generations. Most of the time, young people develop skills more easily when compared to adults due to their current involvement in PE, access to many technologies (e.g., Internet, smart devices), and fewer commitments (Lopes, Stodden, \& Rodrigues, 2017).

\section{Perceptions of PL}

Although most of the respondents were not familiar with the concept of PL, most of them believed PL could help increase PA and prevent non-communicable diseases (NCDs; e.g., obesity, diabetes, cardiac diseases). One of the respondents suggested "PL must be taught to give young people confidence in doing PA," while the older participants mostly agreed that "PL development should begin at home." Studies by Logan et al. (2015) and Whitehead, Durden-Myers, and Pot (2018) also reiterate the importance of developing skills in the early years of life as individuals' competencies in sports skills would increase the likelihood of the individual being active throughout their lifetime. Additionally, some of the respondents pointed out that PL could be taught and developed anywhere, even in a field, school compound, yard, gymnasium, or classroom. A systematic review by van Sluijs et al. (2007) also found many FMS and even complex skills can be developed inside the classroom. Apart from developing PL, many students experience higher academic achievement and on-task behavior due to the integration of PA into classroom learning.

Nonetheless, respondents voiced their concerns on matters related to knowledge, skills, and qualifications. A few of the respondents suggested that it is "impossible to teach PL due to the lack of knowledge," "teaching PL will be much easier if they have the knowledge," "only qualified educators should teach children about PL," and "teachers are not doing enough at school to achieve PE standards, therefore it will be difficult to improve PL." In addition, some of the respondents also associated PL with high-intensity exercise performed to the point of fatigue. The lack of knowledge and exposure may have led to fear and uncertainty among the participants with regard to PL. The International Physical Literacy Association (2017) also suggested a combination of physical competence, motivation, 
and confidence as being crucial to encouraging lifelong participation in PA. Therefore, based on the results, it is important not only for educators but for all individuals to seek knowledge related to PL, as individuals' perceptions are shaped by the knowledge they possess. It is only through knowledge that individuals can truly appreciate and consistently engage in appropriate and safe PA.

\section{Barriers to advocating for PL}

Family values and practices were considered the main determinant of lifetime PA. Most of the participants assumed the importance of PL and PA were majorly influenced by their family upbringing. For example, one of the respondents explained "I did not want my son to be involved in PA as I am afraid he will get hurt when playing," while another respondent pointed to time constraints as barriers to developing PL, "as both of us are working and come back home mostly in the late evening, we rarely have time to spend with our children doing PA." This was supported by previous authors suggesting individuals, especially women, highly value support from friends and family as a factor for them to participate in PA (Hanlon, Khoo, Morris, \& Eime, 2017). Additionally, many young parents also blamed limited playing space and difficulties with committing to and being consistent with engaging in PA with their children. They also tended to place the responsibilities of developing PL solely on educators as they considered themselves less knowledgeable and too inexperienced to teach their own children or the people around them. This was in line with Hanlon et al. (2014), who suggested that perceived community and cultural expectations and backgrounds were determinants for consistent participation in PA. Individuals raised in physically active families would be more likely to become active throughout their lifetimes compared to individuals raised in families with a more sedentary lifestyle.

Some of the participants also suggested a lack of physical energy and social support as barriers in developing PL. Apart from family values, technology (e.g., mobile games, social media) was considered the main barrier to developing PL and a healthy lifestyle among Malaysians. Many participants agreed that the prolonged usage of smart devices has led young people to become lethargic and experience a lack of motivation and physical energy. One of the respondents explained "My son tends to spend most of the evening after school in front of the television or playing online games rather than going outside playing." She also added "I am really concerned about him playing online shooting games and not doing any PA while he is at home." Previous studies on digital data also suggested similar situations in which most Malaysians preferred social networking and chat applications while a minority of individuals, from adolescents to older adults, use technology as a tool to promote PA and improve their PL (Kemp, 2020).

Findings from this study further underscore the findings of Logan et al. (2015), whose study suggested individuals with knowledge of PL tend to have positive perceptions of PL and are more active throughout the day. These individuals are also more likely to be successful in learning motor skills compared to sedentary individuals. The respondent who reported never having heard of PL due to their sedentary lifestyle also underscores the findings of Dudley et al. (2011) on the interrelationship between PL and PA. In other words, lower PL would lead to lower PA. Lower PL would hinder the development of an individual's body coordination, lowering their skill-related fitness (e.g., reaction time, balance, twisting ability) and therefore exposing the individual to higher risks of injury and disease (Logan et al., 2015). Nonetheless, previous studies have shown that sport-based PA specifically would not be sufficient for developing PL as changing the behavior of an individual involves many dynamic factors (Nahas, Goldfine, \& Collins, 2003). This study also found that most of the participants agreed that they can develop PL throughout their lifetime via PA (e.g., gardening, cooking, exercising) rather than just through sports.

Many of the participants seemed to agree that teachers are fully responsible for students' learning, including introducing, explaining, and demonstrating new concepts. As young people in Malaysia spend most of their days at school, teachers have the best opportunity to educate students about PL and encourage PL development (McKenzie, Marshall, Sallis, \& Conway, 2000; Donnelly \& Lambourne, 2011). The content used by teachers, as well as their pedagogy knowledge, could play a valuable role in helping them personalize their teaching methods to address different strengths, weaknesses, and interests among students. This study fully supports the use of a variety of teaching methods and learning aids to attract the interest of students and engage them in learning about and developing PL (Choi et al., 2018). Additionally, appropriate planning, content usage, classroom management, and learning assessments are equally crucial in the development of PL (Lopes et al., 2017).

Nonetheless, this study intends to express the role of social support in the development of PL in young people. Although many of the participants perceived teachers as being mostly responsible for developing PL, many previous studies have suggested that both teachers and parents are important for the development of PL and 
interest in lifetime PA. For instance, a previous study found social support to be an important determinant in PA and lifetime fitness (Beets, Pitetti, \& Forlaw, 2007; Gao, 2012). Hoefer, McKenzie, Sallis, Marshall, and Conway (2001) also looked at parents or other individuals offering social support (e.g., siblings, friends) who accompanied children in PA. They found that children are more likely to be active and feel a greater sense of achievement when these individuals are involved. An initiative led by parents or other individuals offering social support to plan a variety of after-school PA programs would be helpful in giving children the chance to develop PL in a fun and engaging environment (Huang, Gao, Hannon, Schultz, Newton, \& Jenson, 2012). A previous study found that students who participated in an organized PA after-school program recorded more active time and metabolic equivalents compared to students who did not participate in any after-school session of PA (Liu \& ChepyatorThomson, 2004).

\section{Implications for practice}

The results from this study are valuable for teachers, parents, administrators, and policymakers in planning and developing PL among Malaysians. Individuals with high PL tend to be more skillful and have higher self-esteem and motivation to complete daily tasks. Indirectly, this results in higher health quality and could thus reduce the nation's NCD statistics. Emphasizing the fulfillment of survival needs (i.e., fun, movement, freedom), teachers should modify aspects such as playing areas, equipment, and instructions to enhance their teaching methods and tailor them to accommodate students' needs, strengths, and weaknesses (Lengel \& Kuczala, 2018). Parents should also strive to invest more time doing PA with their children. They should spend this time engaging with them and creating games which integrate the elements of fun, activity, problem solving, and communication. In addition, parents should provide equipment that helps children be active and stimulates their interest in engaging in PA. Several authors have also stressed the importance of having sufficient and suitable equipment to stimulate young people to engage in PA and develop lifetime PL (Verstraete, Cardon, De Clercq, \& De Bourdeaudhuij, 2006).

Additionally, administrators and policymakers in Malaysia should also place greater importance on promoting lifetime fitness among Malaysians and emphasize that "prevention is better than medicine" through investment in providing the facilities, amenities, and professional development workshops for teachers and parents to better educate them about the potential of PL. The maintenance of these facilities and enforcement of current policies on PA are equally important as behavior change is a long and dynamic process (Nahas et al., 2003). Policymakers should also consider having a topic on integrating technology into PE in the current national school textbook to accentuate the utilization of technology in the classroom as well as in PE.

The results of this study stress that more studies need to done in the future, particularly on the development of inclusive and age-appropriate learning structures as well as the development of assessment tools to assess PL levels among Malaysians. The author assumes the criteria and measurement methods used in the West (e.g., McCarron Assessment of Neuromuscular Development [MAND] in Northern Ireland, School Sport Survey in Wales [Spengler, 2015]) would yield different results among Malaysians due to differences in geography, demographics, skill levels, and initial knowledge factors. A couple of limitations to the study include its small sample size, absence of skill tests, and lack of participation from other ethnicities in Malaysia.

\section{Conclusion}

This study provides teachers with insight about PL awareness in Malaysia and can inform their future practice to focus more on using innovative strategies (student-centered learning, practice structures, reciprocal teaching). Personalized learning experiences can help students gain confidence, reduce their fear of failure, and gain interest in engaging in PA. These efforts would then help improve students' learning engagement and strengthen the connection between the concept and actual situations. This study demonstrated that the current knowledge of PL in Malaysia is average, which influences Malaysians' perception of the importance of PL in overall development. Additionally, the majority of the participants agreed that family upbringing and excessive use of technology are the main challenges to overcome when improving PL and wellness across levels of society in Malaysia. 


\section{Ethics approval and informed consent}

This study was approved by the Research Ethics Committee of the Universiti Teknologi MARA (UiTM).

\section{Competing interests}

There is no conflict of interest in this study.

\section{Funding}

This study did not receive any forms of funding.

\section{Acknowledgments}

The authors wish to express gratitude to the Faculty of Health Sciences and Faculty of Education, UiTM for their support, including their time, advice, and logistical support in helping ensure this study was successfully completed.

\section{References}

Barnett, A. L., Dawes, H., \& Wilmut, K. (2012). Constraints and facilitators in participation in physical activity in teenagers with developmental coordination disorders: An exploratory interview study. Child: Care, Health and Development, 39, 393-403.

Beets, M. W., Pitetti, K. H., \& Forlaw, L. (2007). The role of self-efficacy and referent specific social support in promoting rural adolescent girls' physical activity. American Journal of Health Behavior, 31(3), 227-237.

Bowden Davies, K. A., Pickels, S., Sprung, V. S., Kemp, G. J., Alam, U., et al. (2019). Reduced physical activity in young and older adults: Metabolic and musculoskeletal implications. Therapeutic Advances in Endocrinology and Metabolism, 10, 1-15.

Castilli, D. M. \& Valley, J. A. (2007). Chapter 3: The relationship of physical fitness and motor competence to physical activity. Journal of Teaching in Physical Education, 26(4), 358-374.

Choi, S. M., Sum, R. K. W., Leung, E. F. L., \& Ng, R. S. K. (2018). Relationship between perceived physical literacy and physical activity levels among Hong Kong adolescents. PLoS ONE, 13(8), 1-11.

Cooper, J. O., Heron, T. E., \& Heward, W. L. (2007). Applied Behavior Analysis (2 ${ }^{\text {nd }}$ ed.). Upper Saddle River, NJ: Pearson/Merrill-Prentice Hall.

Cools, W., Martelaer, K. D., Samaey, C., \& Andries, C. (2009). Movement skill assessment of typically developing preschool children: A review of seven movement skill assessment tools. Journal of Sports Science and Medicine, 8, $154-168$

Department of Statistics Malaysia. (2019). Social statistics bulletin 2019. https://www.dosm.gov.my/v1/index.php?r=column/pdfPrev\&id=eVZ5NnJPMm5PTEFxbVdWcERzdGNrZz09

Donnelly, J. E. \& Lambourne, K. (2011). Classroom-based physical activity, cognition, and academic achievement. Preventive Medicine, 52, S36-S42.

Dudley, D., Okley, A., Pearson, P., \& Cotton, W. (2011). A systematic review of the effectiveness of physical education and sport interventions targeting physical activity, movement skills and enjoyment of physical activity. European Physical Education Review, 17(3), 353-378.

Ennis, C. (2010). On their own: Preparing students for a lifetime. Journal of Physical Education, Recreation \& Dance, 81(5), 17-22.

Feguera, R. \& An, R. (2017). Motor skill competence and physical activity in pre-schoolers: A review. Maternal and Child Health Journal, 2(1), 136-146.

Gao, Z. (2012). Urban Latino school children's physical activity correlates and daily physical activity participation: A social cognitive perspective. Psychology, Health and Medicine, 1-9.

Graham, G. (2015). The fall and rise of physical education. PE Central: What Works in Physical Education (Special Issue), 1-8.

Hanlon, C., Khoo, S., Morris, T., \& Eime, R. (2017). Factors influencing women in physical activity programs in Malaysia. Health Promotion International, 34(3), 389-399.

Hardy, L., King, L., Espinel, P., Cosgrove, C., \& Bauman, A. (2010b). NSW Schools Physical Activity and Nutrition Survey (SPANS). Full report. Sydney: NSW Ministry of Health. 
Hardy, L., King, L., Farrell, L., Macniven, R., \& Howlett, S. (2010a). Fundamental movement skills among Australian preschool children. Journal of Science and Medicine in Sport, 13(5), 503-508.

Harten, N., Olds, T., \& Dollman, J. (2008). The effects of gender, motor skills and play area on free play activities of 8-11 year old school children. Health \& Place, 14(3), 386-393.

Hoefer, W. R., McKenzie, T. L., Sallis, J. F., Marshall, S. J., \& Conway, T. L. (2001). Parental provision of transportation for adolescent physical activity. American Journal of Preventive Medicine, 21, 48-51.

Huang, C., Gao, Z., Hannon, C. J., Schultz, B., Newton, M., \& Jenson, W. (2012). Impact of an after-school physical activity program on youth's physical activity correlates and behavior. Journal of Research in Health, Physical Education, Recreation, Sport \& Dance, 7(1), 18-23.

Kemp, S. (2020). Digital 2020: Malaysia. Datareportal. https://atareportal.com/reports/digital-2020-malaysia

Khoo, S., Poh, B. K., Suhaimi, S. A., Chong, K. H., \& Varela, A. R. (2020). Physical activity promotion in Malaysia: Challenges and opportunities. Frontiers in Public Health, 8, 1-5.

Kuczala, M. \& Lengel, T. (2018). Ready, set, go!: The kinesthetic classroom 2.0 (2 $2^{\text {nd }}$ ed.). Thousand Oaks, CA: Corwin.

Levin, K. A. (2006). Study design III: Cross-sectional studies. Evidence-Based Dentistry, 7, 24-25.

Liu, W. \& Chepyator-Thomson, J. R. (2004). Contribution of organized sports to physical activity level: A middle school as a case. Research Quarterly for Exercise and Sport, 75(suppl.), A-72.

Logan, S. W., Webster, E. K., Gretchell, N., Pfeiffer, K. A., \& Robinson, L. E. (2015). Relationship between fundamental motor skill competence and physical activity during childhood and adolescence: A systematic review. Kinesiology Review, 4(4), 416-426.

Lopes, V. P., Stodden, D. F., \& Rodrigues, L. P. (2017). Effectiveness of physical education to promote motor competence in primary school children. Physical Education and Sport Pedagogy, 22(6), 589-602.

Martinek, T. (2017). Enhancing youth development programs through logic model assessment. Revista Internacional de Ciencias del Deporte, 13(49), 302-316.

Martinek, T., Holland, B., \& Seo, G. (2019). Understanding physical activity engagement in students: Skills, values, and hope. Revista Internacional de Ciencias del Deporte, 55(15), 88-101.

Marton, F. (2015). Necessary conditions of learning. New York, NY: Routledge.

McKenzie, T. L., Marshall, S. J., Sallis, J. F., \& Conway, T. L. (2000). Student activity levels, lesson context, and teacher behaviour during middle school physical education. Research Quarterly for Exercise and Sport, 71, $249-259$.

Mills, G. E. (2014). Action research: A guide for the teacher researcher ( $5^{\text {th }}$ ed.). Boston, MA: Pearson.

Mitchell, B., McLennan, S., Latimer, K., Graham, D., Gilmore, J., \& Rush, E. (2013). Improvement of fundamental movement skills through support and mentorship of class room teachers. Obesity Research \& Clinical Practice, 7(3), 230-234.

Ministry of Education Malaysia. (2019). Buku panduan pengurusan mata pelajaran tahun 2019. https://www.moe.gov. $\mathrm{my} / \mathrm{en} / \mathrm{moe}$-staff/education-services-officer/buku-panduan-pengurusan-mata-pelajaran-tahun-2019

Mosston, M. \& Ashworth, S. (1990). The spectrum of teaching styles: From command to discovery. New York, NY: Longman.

Nahas, M. V., Goldfine, B., \& Collins, M. (2003). Determinants of physical activity in adolescents and young adults: The basis for high school and college physical education to promote active lifestyles. Physical Educator, 60(1), $42-56$.

O’Brian, W., Belton, S., \& Issartel, J. (2016). Fundamental movement skills proficiency among adolescent youth. Physical Education and Sport Pedagogy, 21(6), 557-571.

Pietkiewicz, I. \& Smith, J. A. (2014). A practical guide to using Interpretive Phenomenological Analysis in qualitative research psychology. Psychological Journal, 20(1), 7-14.

Seligman, M. (2002). Authentic happiness: Using the new positive psychology to realize your potential for lasting fulfilment. New York, NY: Free Press.

Sharma, G. (2017). Pros and cons of different sampling techniques. International Journal of Applied Research, 3(7), 749-752.

Spengler, J. O. (2015). Physical literacy: A global environmental scan. Washington, DC: The Aspen Institute.

Ulrich, D. (2000). Test of gross motor development 2: Examiner's manual (2nd ed.). Austin, TX: PRO-ED.

van Sluijs, E. M. F., McMinn, A. M., \& Griffin, S. J. (2007). Effectiveness of interventions to promote physical activity in children and adolescents: Systematic review of controlled trials. British Medical Journal, 1-13. doi: 10.1136/ bmj.39320.843947.BE.

Verstraete, S. J. M., Cardon, G. M., De Clercq, D. L. R., \& De Bourdeaudhuij, I. M. M. (2006). Increasing children’s physical activity levels during recess periods in elementary schools: The effects of providing game equipment. European Journal of Public Health, 16(4), 415-419. 
Woods, J. A., Hutchinson, N. T., Powers, S. K., Roberts, W. O., Gomez-Cabrera, M. C., et al. (2020). The COVID-19 pandemic and physical activity. Sports Medicine and Health Science, 2(2), 55-64.

World Health Organization. (2019). Sugary drink tax important first step, but obesity in Malaysia demands further action. https://www.who.int/malaysia/news/commentaries/detail/sugary-drinks-tax-important-first-step-but-obesity-inmalaysia-demands-further-action

Whitehead, M. (2016). International Physical Literacy Association. Retrieved from https://www.physical-literacy.org.uk.

This is Open Access article distributed under the terms of CC-BY-NC-ND 4.0 International License. 